\title{
Clinical and Radiographic Alterations in Bilateral Avascular Necrosis of the Femoral Head Following Laser Acupuncture: A Case Report
}

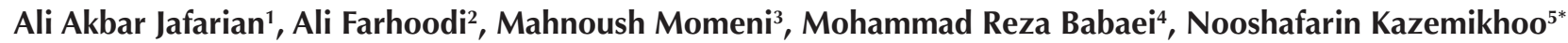 \\ 'Department of Anesthesiology and Pain, Shahid Motahhari Hospital of Trauma and Burning Center, Iran University of \\ Medical Sciences and Health Services, Tehran, Iran \\ ${ }^{2}$ Burn Plastic Surgery, Shahid Motahhari Hospital of Trauma and Burning Center, Iran University of Medical Sciences and \\ Health Services, Tehran, Iran \\ ${ }^{3}$ Burn Research Center, Department of Plastic and Reconstructive Surgery, Iran University of Medical Sciences, Tehran, Iran \\ ${ }^{4}$ Interventional Fellowship of Radiology, Firoozgar Hospital, Iran University of Medical Sciences and Health Services, \\ Tehran, Iran \\ ${ }^{5}$ Laser Application in Medical Sciences Research Center, Shahid Beheshti University of Medical Sciences, Tehran, Iran
}

\section{*Correspondence to \\ Nooshafarin Kazemikhoo, Laser Application in Medical Sciences Research Center, Shahid Beheshti University of Medical Sciences, Tehran, Iran Tel \& Fax: +98 2122749221 Email: nooshakazemi@gmail.com}

\begin{abstract}
Introduction: Avascular necrosis (AVN) of the femoral head is an increasingly common cause of musculoskeletal disability with unknown etiology. Traumatic and non-traumatic factors can be effective in its occurrence. About $50 \%$ of cases are bilateral. The underlying treatment is prosthetic replacement surgical procedure.

Case Presentation: We report a case of bilateral AVN of femoral heads who was a candidate for prosthetic replacement surgery but improved significantly, using laser acupuncture. The patient was a 55-year-old woman with a diagnosis of bilateral osteonecrosis of the femoral head for five years. As the patient declined the surgical option, laser acupuncture was started for pain control. Regarding the signs of bilateral femoral head recovery (according to the MRI scan criteria), a total of 3 courses of laser acupuncture (each course was 20 sessions) with 2 months intervals was performed. Ten acupuncture points: Li4, Li11, St36, SP6, LIV3, GB4, GB5, GB6, GB13, GB14, GB20, GB30, GB31, GB34, were irradiated bilaterally using red $650 \mathrm{~nm}$ laser, $100 \mathrm{~mW}$, $1505 \mathrm{~Hz}$ frequency, duty cycle $503 \mathrm{~J} /$ point and near infrared $810 \mathrm{~nm}$ laser, $100 \mathrm{~mW}, 1705 \mathrm{~Hz}$ frequency, duty cycle $503 \mathrm{~J} /$ point, for 2 minutes. The patient received 3 laser therapy courses. During the first-course, laser therapy was done every other day to reduce pain. For the second and third courses, according to pain decrease, therapy was done every week.

Results: The results of the MRI scans and x-ray studies show progressive regeneration of the right femoral head from VI to B II and of the left from V to C II (based on the standard table of Pennsylvania).

Conclusion: It seems that this procedure may be mentioned in future research projects, especially in cases with high risks of surgery.

Keywords: Avascular necrosis; Femoral head; Laser acupuncture; Regenerative medicine.
\end{abstract}

\section{Introduction}

Avascular necrosis (AVN) is the final common pathway resulting from insufficient blood supply to the bone, commonly to the femoral head. It affects young and active adults and is characterized by decreased vascular supply to the subchondral bone of the femoral head, leading to the destruction and collapse of the femoral head. There are many postulated etiologies of non-traumatic AVN, including corticosteroids, bisphosphonates, and radiotherapy. AVN of the femoral head (FHAVN) is an increasingly common cause of musculoskeletal disability, and it poses a major diagnostic and therapeutic challenge.
Although patients are initially asymptomatic, AVN of the femoral head usually progresses to joint destruction, requiring total hip replacement, usually before the fifth decade. ${ }^{1,2}$

Although radiography, scintigraphy, computed tomography (CT), and magnetic resonance imaging (MRI) have been widely used in the diagnosis of FHAVN, positron emission tomography (PET) has recently been evaluated to assess the vascularity of the femoral head. ${ }^{3}$ Various treatments have been suggested for this pathologic condition including total hip arthroplasty, cell therapy with mesenchymal stromal cells, ${ }^{4}$ trans-trochanteric

Please cite this article as follows: Jafarian AA, Farhoodi A, Momeni M, Babaei MR, Kazemikhoo N. Clinical and radiographic alterations in bilateral avascular necrosis of the femoral head following laser acupuncture: a case report. J Lasers Med Sci. 2018;9(2):149-153. doi:10.15171/jlms.2018.28. 
rotational osteotomy, ${ }^{5}$ using novel calcium phosphate (CPC) composite scaffold, which contains BMP-VEGFloaded poly-lactic-co-glycolic acid microspheres, ${ }^{6}$ core decompression and autologous bone marrow concentrate, ${ }^{3}$ and tensor fascia lata muscle pedicle grafting. ${ }^{7}$

Some evidence shows that low-level laser irradiation can improve wound healing ${ }^{8,9}$ and pain relief in patients with temporomandibular joint disorders, ${ }^{10}$ and may successfully be used in treatment of some pathological conditions like Achilles tendon injury in animal models, ${ }^{11}$ cartilage defects, ${ }^{12}$ experimental septic arthritis, ${ }^{13}$ inflammatory and rheumatic diseases, ${ }^{14}$ and other musculoskeletal lesions. Some clinical randomized control trials report the effectiveness of LLLT in musculoskeletal pains. ${ }^{15,16}$

One of the methods in laser therapy is laser acupuncture, which has been developing since 30 years ago. In this method; laser light is used to stimulate acupuncture points instead of a needle. Review articles show that this method is effective in myofascial pain, chronic tension headache, and post-operative nausea and vomiting. ${ }^{17}$ In our previous study, we used this method along with local laser irradiation to treat diabetic foot ulcers. ${ }^{8}$

Here for the first time, we report a case of FHAVN candidate for prosthetic replacement surgery who improved significantly after 3 long courses of laser acupuncture.

\section{Case Presentation}

The patient was a 55-year-old woman with a diagnosis of bilateral osteonecrosis of the femoral head (ONFH) since 5 years ago. The patient was a candidate for prosthetic replacement surgery but declined the surgical option and was referred to the pain clinic for pain control in 2014. The patient's history revealed that pain in the right hip started approximately five years prior to referral and progressed over time. Pain in the left hip also added after 6 months. Initially, the patient was treated by rheumatologists with conservative methods that included resting, limiting activity, using acetaminophen, calcium and, vitamin D3 medications. Eventually, due to a progressive sensation of pain and restriction of movement, she was referred for orthopedic measures.

Diagnostic blood tests were as follows:

$\mathrm{CBC}$ test results: $\mathrm{RBC}=4500000, \mathrm{Hg}=13.4, \mathrm{Hct}=41 \%$

$\mathrm{WBC}=6600$, Neut. $=41 \%$, Lymph $=53 \%$, Eos. $=4 \%$, Mono. $=2 \%$

Blood biochemistry profile:

$\mathrm{AS} 0=$ neg $, \mathrm{CRP}=+1, \mathrm{ESR}=22 \mathrm{~mm} / \mathrm{h}, \mathrm{ANA}=\mathrm{neg}, \mathrm{Ca}$ (total) $=9.2 \mathrm{mg} / \mathrm{dL}$, Ionized $\mathrm{Ca}=1.36 \mathrm{mg} / \mathrm{dL}$, alkaline phosphatase $=280 \mathrm{U} / \mathrm{L}, \mathrm{FBS}=96 \mathrm{mg} / \mathrm{dL}$, triglyceride $=178$ $\mathrm{mg} / \mathrm{dL}$, cholesterol $=148 \mathrm{mg} / \mathrm{dL}$, Uric acid $=5.6 \mathrm{mg} / \mathrm{dL}$.

Bilateral hip x-ray reports presented bilateral hip destruction and bilateral deformity at the femoral neck. These changes were more obvious on the right side. Meanwhile, MRI scan report revealed severe deformity, bilateral disappearance of femoral heads and also reduction in the joint space. According to the Pennsylvania University criteria, ${ }^{18}$ bilateral destruction of the femoral head was equivalent to Stage VI at the right side, and Stage V at the left side, respectively. Before starting the treatment procedure, the pain scores were about 4-5, during the break and 6-7, in an upright position (based on the visual analogous scale [VAS] criteria). Limitations in range of motion were as follows:

1. Passive movements at the right side: Abduction $=13^{\circ}$, adduction $=15^{\circ}$, extension $=15^{\circ}$, flexion $=40^{\circ}$, internal rotation (rotation in flexion of hip) $=13^{\circ}$, External rotation $($ rotation in flexion of hip $)=15^{\circ}$

2. Active range of motion in the right hip was as follows: $\mathrm{Ab}$ duction $=13^{\circ}$, adduction $=17^{\circ}$, extension $=15^{\circ}$, flexion $=50^{\circ}$, internal rotation (rotation in flexion of hip) $=20^{\circ}$, external rotation (rotation in flexion of hip) $=20^{\circ}$

Considering the severity of the complications, surgical replacement of bilateral femoral head was initially offered. Despite repeated recommendations for surgery, and merely because of the patients' reluctance, she was referred to our pain management clinic. Then, just for pain control and in compliance with all contraindications, laser acupuncture was recommended after patient's informed consent.

Ten acupuncture points: Li4, Li11, St36, SP6, LIV3, GB4, GB5, GB6, GB13, GB14, GB20, GB30, GB31, GB34, ${ }^{19}$ were irradiated bilaterally using red $650 \mathrm{~nm}$ laser, $100 \mathrm{~mW}$, $1505 \mathrm{~Hz}$ frequency, duty cycle 50 and near infrared 810 $\mathrm{nm}$ laser, $100 \mathrm{~mW}, 1705 \mathrm{~Hz}$ frequency, duty cycle 50 for 2 minutes. The patient received 3 laser therapy courses with 2 months intervals. Each course had 20 sessions. During the first-course laser therapy was done every other day to reduce pain. For the second and third courses, according to pain reduction, therapy was done every week.

The results of laser therapy after the end of the first treatment period showed that pain scores at rest and during activity reached to 3-4 during the break and 4-5, in an upright position (based on the VAS Criteria). The range of motion of both sides was as follows:

1. Passive movements at the right side: Abduction $=13^{\circ}$, adduction $=15^{\circ}$, extension $=17^{\circ}$, flexion $=50^{\circ}$, internal rotation (rotation in flexion of hip) $=13^{\circ}$, external rotation (rotation in flexion of hip $)=15^{\circ}$.

2. Active range of motion in the right hip was as follows: Abduction $=13^{\circ}$, adduction $=17^{\circ}$, extension $=17^{\circ}$, flexion $=$ $55^{\circ}$, internal rotation (rotation in flexion of hip) $=13^{\circ}$, external rotation (rotation in flexion of hip) $=15^{\circ}$.

At the end of the second course of treatment, pain scores during the break and during activity were equivalent to 1-2 or 2-3, respectively. Subsequently and after a pause period (for 6 weeks), MRI scan was ordered for both hip joints. The results showed deformity reduction of the right and left femoral head went from Stage VI to V and from $\mathrm{V}$ to $\mathrm{IV}$, respectively.

After completion of the second period, laser therapy was discontinued for 8 weeks. Then, the treatment was 
repeated again for 20 sessions once a week. At the end of the third course of laser therapy, pain scores at break time and during activity diminished to 0 and $0-1$, respectively. Then, MRI scan of both hip joints revealed that femoral head deformity on the right and left sides moved from Stage V to III and from IV to III, respectively.

Although laser therapy was primarily started in order to reduce pain, due to deformity recovery of the bilateral femoral necks, the second and third courses also continued with informed consent from the patient and hip surgeon consultation. The results of the latest report of the MRI scan showed that the femoral head deformity on the left and right sides reached IIB and IIC, respectively. Pain scores at break time and during routine activities were 0 . Hip movement limitations on each side were as follows: 1. Passive movements at the right side: Abduction $=24^{\circ}$, adduction $=25^{\circ}$, extension $=21^{\circ}$, flexion $=50^{\circ}$, internal rotation (rotation in flexion of hip) $=13^{\circ}$, external rotation (rotation in flexion of hip) $=15^{\circ}$

2. Active range of motion in the right hip was as follows: Abduction $=26^{\circ}$, adduction $=27^{\circ}$, extension $=23^{\circ}$, flexion $=$ $80^{\circ}$, internal rotation (rotation in flexion of hip) $=13^{\circ}$, external rotation (rotation in flexion of hip) $=17^{\circ}$

3. Passive range of motion in the left hip was: Abduction= $25^{\circ}$, adduction $=26^{\circ}$, extension $=23^{\circ}$, flexion $=86^{\circ}$, internal rotation (rotation in flexion of hip) $=13^{\circ}$, external rotation $($ rotation in flexion of hip $)=15^{\circ}$

4. Active range of motion in the right hip was as follows: Abduction $=27^{\circ}$, adduction $=26^{\circ}$, extension $=24^{\circ}$, flexion $=$ $86^{\circ}$, internal rotation (rotation in flexion of hip) $=13^{\circ}$, external rotation (rotation in flexion of hip) $=20^{\circ}$.

Before and after therapy X-rays and MRIs are shown in Figures 1-3.

Follow up: This report is being written 10 months after the end of the third course of therapy and the patient is being visited every 2 months since then. Pain score at break time and during routine activities was 0 , but 1 during excessive activities.

\section{Discussion}

This case of FHAVN improved significantly after a prolonged course of laser acupuncture. However, in some orthopedic sources, noninvasive treatments like inhalation of hyperbaric oxygen, mesenchymal stromal cell therapy, gene therapy carrying growth factor, and vascular endothelial growth factor ${ }^{20,21}$ have been mentioned, but to the best of our knowledge, it is the first report using low-level laser therapy as a treatment for AVN of the femoral head. It seems that this study has been able to show the effect of LLLT on AVN treatment, for the first time. In addition to pain control, results showed that the destruction of the femoral head was stopped and bone lesion severity on the right and left moved from Stage V, VI to IIC and IIB, respectively (based on University of Pennsylvania classification) and pain scores at break time and during routine activities were 0 .
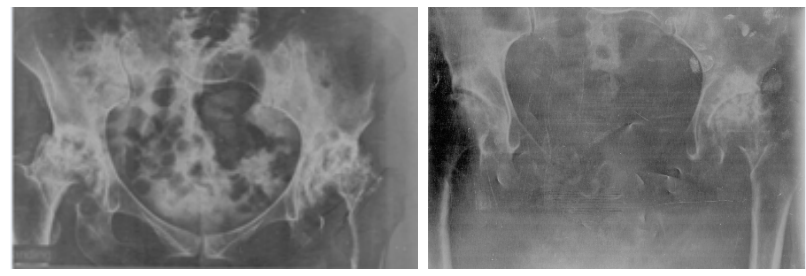

Figure 1. Left: X-Ray Before Laser Therapy, Right: X-Ray After Laser Therapy.
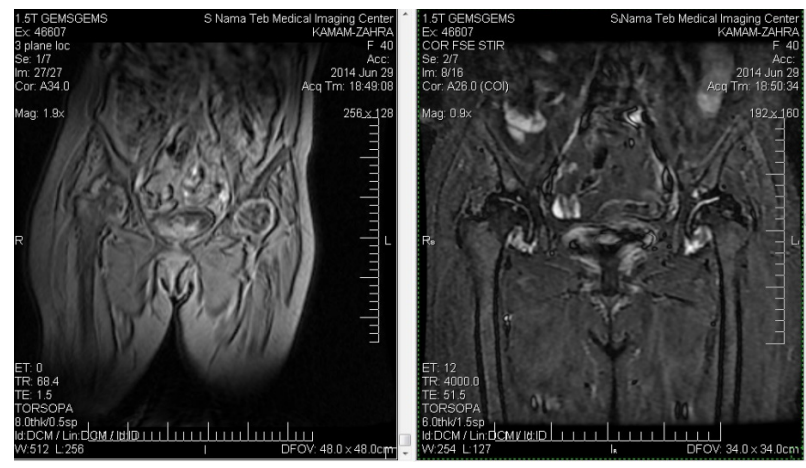

Figure 2. MRI Before Treatment.
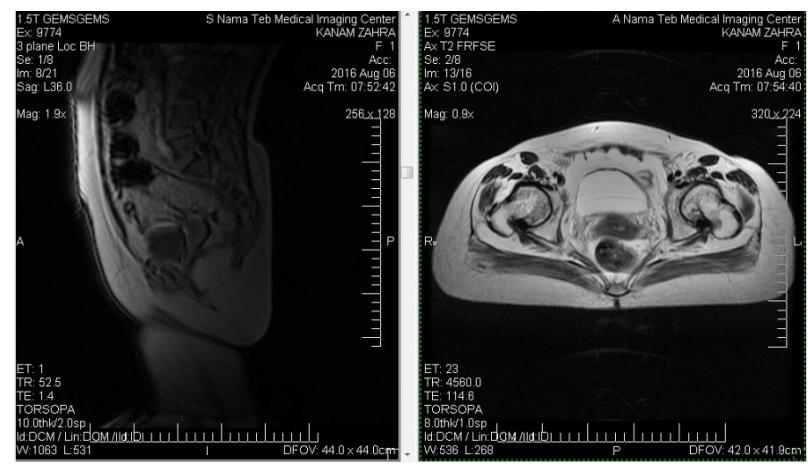

Figure 3. MRI After Treatment.

Nearly 6 decades after the first use of lasers for various applications in different branches, medical usage of various forms of laser has found a special place. Since 1988, there are reports on ulcers and bone healing effects of lasers. Studies show that laser therapy increases blood supply, stimulate biological processes and affects growth factors and chemical agents involved in wound healing. It also has positive effects on the immune system, inflammation and edema reduction. . $^{8,914,22,23}$

Several meta-analyses and reviews suggest low-level laser therapy as an effective therapeutic modality for wound healing. ${ }^{24,25}$ Joensen et al reported the efficacy of laser therapy on Achilles tendon injury in rats. They reported tendon thickness in laser treated compared to control group. ${ }^{11}$ Our previous study showed that irradiation of infra-red $810 \mathrm{~nm}$ laser on cultured fibroblast of the skin of diabetic and non-diabetic mice significantly increases fibroblast growth factor (FGF) gene expression in diabetic 
mice. Although laser irradiation increased the expression of vascular endothelial growth factor (VEGF) and platelet derived growth factor (PDGF) too, it was not statistically significant. ${ }^{22}$ Our other studies showed that laser therapy on diabetic neuropathic pain has a significant effect on pain reduction. ${ }^{26}$

Some studies suggest acupuncture as a pain control adjuvant. Crespin et al reported that acupuncture along with pharmacological therapy can be used after total joint replacement surgery. ${ }^{27}$ Set et al reported full recovery of a case with Legg-Calve-Perthes disease using laser acupuncture. ${ }^{19}$

Baxter et al reviewed the effectiveness of laser acupuncture in a systematic review. They reported that laser acupuncture could be effective in the management of chronic tension headache, myofascial pain, and postoperative nausea and vomiting (17). Haker and Lundeberg reported the efficacy of laser acupuncture for lateral humeral epicondylalgia in a double-blind study. ${ }^{28}$ In our previous study, we used this method along with local laser irradiation to treat diabetic foot ulcers. ${ }^{8}$ Patients, who were candidates for amputation, healed completely using this combination therapy.

\section{Conclusion}

The results of this case report suggest that laser acupuncture might be used for pain reduction and even regeneration of femoral head in FHAVN.

\section{Conflict of Interests}

The authors have no conflict of interest to declare.

\section{Ethical Considerations}

Written informed consent was obtained from the patient for publishing this case report.

\section{References}

1. Wenger D, Samuelsson H, Duppe H, Tiderius CJ. Early treatment with the von Rosen splint for neonatal instability of the hip is safe regarding avascular necrosis of the femoral head: 229 consecutive children observed for 6.5 years. Acta Orthop. 2016;87(2):169-175. doi:10.3109/17453674.2015.1 126158

2. Daoud AM, Hudson M, Magnus KG, et al. Avascular Necrosis of the Femoral Head After Palliative Radiotherapy in Metastatic Prostate Cancer: Absence of a Dose Threshold? Cureus. 2016;8(3):e521. doi:10.7759/cureus.521

3. Pepke W, Kasten P, Beckmann NA, Janicki P, Egermann M. Core Decompression and Autologous Bone Marrow Concentrate for Treatment of Femoral Head Osteonecrosis: A Randomized Prospective Study. Orthop Rev (Pavia). 2016;8(1):6162. doi:10.4081/or.2016.6162

4. Castro FP Jr, Barrack RL. Core decompression and conservative treatment for avascular necrosis of the femoral head: a meta-analysis. Am J Orthop (Belle Mead NJ). 2000;29(3):187-194.

5. Nakashima Y, Yamamoto T, Fukushi JI, et al. Transtrochanteric rotational osteotomy for avascular necrosis of the femoral head after unstable slipped capital femoral epiphysis: 10-year clinical results. J Orthop Sci. 2016;21(6):831-835. doi:10.1016/j.jos.2016.06.014

6. Zhang HX, Zhang XP, Xiao GY, et al. In vitro and in vivo evaluation of calcium phosphate composite scaffolds containing BMP-VEGF loaded PLGA microspheres for the treatment of avascular necrosis of the femoral head. Mater Sci Eng C Mater Biol Appl. 2016;60:298-307. doi:10.1016/j. msec.2015.11.055

7. Ashraf M, Subramanian V, Narayanan S, Mohan M. Tensor fascia lata muscle pedicle grafting for avascular necrosis femoral head. Int J Res Orthop. 2016;2(4):333-339. doi:10.18203/issn.2455-4510.IntJResOrthop20164164

8. Kazemi-Khoo N. Successful treatment of diabetic foot ulcers with low-level laser therapy. Foot. 2006;16(4):184187. doi:10.1016/j.foot.2006.05.004

9. Dahmardehei M, Kazemikhoo N, Vaghardoost R, et al. Effects of low level laser therapy on the prognosis of splitthickness skin graft in type 3 burn of diabetic patients: a case series. Lasers Med Sci. 2016;31(3):497-502. doi:10.1007/ s10103-016-1896-9

10. Maia ML, Bonjardim LR, Quintans Jde S, Ribeiro MA, Maia LG, Conti PC. Effect of low-level laser therapy on pain levels in patients with temporomandibular disorders: a systematic review. J Appl Oral Sci. 2012;20(6):594-602.

11. Joensen J, Gjerdet NR, Hummelsund S, Iversen V, LopesMartins RA, Bjordal JM. An experimental study of lowlevel laser therapy in rat Achilles tendon injury. Lasers Med Sci. 2012;27(1):103-111. doi:10.1007/s10103-011-0925-y

12. Zati A, Desando G, Cavallo C, et al. Treatment of human cartilage defects by means of Nd:YAG Laser Therapy. J Biol Regul Homeost Agents. 2012;26(4):701-711.

13. Araujo BF, Silva LI, Meireles A, et al. Effects of LowLevel Laser Therapy, $660 \mathrm{~nm}$, in Experimental Septic Arthritis. ISRN Rheumatol. 2013;2013:341832. doi:10.1155/2013/341832

14. Lopes-Martins RA, Penna SC, Joensen J, Iversen VV, Bjordal JM. Low Level Laser Therapy [LLLT] in Inflammatory and Rheumatic Diseases:A Review of Therapeutic Mechanisms. Curr Rheumatol Rev. 2007;3(2):147-154. doi:10.2174/157339707780619421

15. Gur A, Sarac AJ, Cevik R, Altindag O, Sarac S. Efficacy of $904 \mathrm{~nm}$ gallium arsenide low level laser therapy in the management of chronic myofascial pain in the neck: a double-blind and randomize-controlled trial. Lasers Surg Med. 2004;35(3):229-235. doi:10.1002/lsm.20082

16. Goldman JA, Chiapella J, Casey H, et al. Laser therapy of rheumatoid arthritis. Lasers Surg Med. 1980;1(1):93-101.

17. Baxter GD, Bleakley C, McDonough S. Clinical effectiveness of laser acupuncture: a systematic review. $J$ Acupunct Meridian Stud. 2008;1(2):65-82. doi:10.1016/ s2005-2901(09)60026-1

18. Banaszkiewicz PA. Idiopathic Bone Necrosis of the Femoral Head. Early Diagnosis and Treatment. In: Banaszkiewicz PA, Kader DF, eds. Classic Papers in Orthopaedics. London: Springer; 2014:121-123.

19. Set T, Maras I, Khan AS, Ozdemir H. Management of Legg-Calve-Perthes disease with acupuncture: a case report. Acupunct Med. 2013;31(1):105-107. doi:10.1136/ acupmed-2012-010255

20. Calori GM, Mazza E, Colombo A, Mazzola S, Colombo M. Core decompression and biotechnologies in the treatment of avascular necrosis of the femoral head. EFORT Open Rev. 2017;2(2):41-50. doi:10.1302/2058-5241.2.150006 
21. Ciapetti G, Granchi D, Fotia C, et al. Effects of hypoxia on osteogenic differentiation of mesenchymal stromal cells used as a cell therapy for avascular necrosis of the femoral head. Cytotherapy. 2016;18(9):1087-1099. doi:10.1016/j. jcyt.2016.06.005

22. Khoo NK, Shokrgozar MA, Kashani IR, et al. In vitro Therapeutic Effects of Low Level Laser at mRNA Level on the Release of Skin Growth Factors from Fibroblasts in Diabetic Mice. Avicenna J Med Biotechnol. 2014;6(2):113118.

23. Schindl A, Schindl M, Pernerstorfer-Schon H, Schindl L. Low-intensity laser therapy: a review. J Investig Med. 2000;48(5):312-326.

24. Woodruff LD, Bounkeo JM, Brannon WM, et al. The efficacy of laser therapy in wound repair: a meta-analysis of the literature. Photomed Laser Surg. 2004;22(3):241-247. doi:10.1089/1549541041438623
25. Beckerman $\mathrm{H}$, de Bie RA, Bouter LM, De Cuyper HJ, Oostendorp RA. The efficacy of laser therapy for musculoskeletal and skin disorders: a criteria-based meta-analysis of randomized clinical trials. Phys Ther. 1992;72(7):483-491.

26. Khamseh ME, Kazemikho N, Aghili R, et al. Diabetic distal symmetric polyneuropathy: effect of low-intensity laser therapy. Lasers Med Sci. 2011;26(6):831-835. doi:10.1007/ s10103-011-0977-z

27. Crespin DJ, Griffin KH, Johnson JR, et al. Acupuncture provides short-term pain relief for patients in a total joint replacement program. Pain Med. 2015;16(6):1195-1203. doi:10.1111/pme.12685

28. Haker E, Lundeberg T. Laser treatment applied to acupuncture points in lateral humeral epicondylalgia. A double-blind study. Pain. 1990;43(2):243-247. 